\title{
The Impact Of Information Technology Investments On Managerial Decision Making: Evidence From Dividend Payout
}

T. Selwyn Ellis, (Email: ellis@cab.latech.edu), Louisiana Tech University K. Michael Casey, (Email: caseym@hsu.edu), Henderson State University

Hani I. Mesak, (Email: mesak@cab.latech.edu), Louisiana Tech University

\begin{abstract}
Investments in Information Technology (IT) are an increasing part of organizational expenditures in spite of the fact that there is little evidence in the existing literature that suggests these investments are related to the organization's performance. The uncertainty of IT investment payoff should be reflected in other managerial decisions. This research examines Rozeff's (1982) agency cost/transaction cost tradeoff model to determine if IT investments are related to dividend payout ratios for an organization. A dividend payout model including an IT investment variable is estimated. The estimation results suggest that a significant positive relationship exists between dividend payout and a firm's IT investments.
\end{abstract}

\section{Introduction}

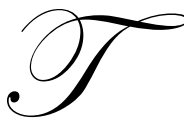

he significance of the information technology (IT) function in organizations is growing rapidly as organizations strive to build more effective processes and become more competitive. This fact, coupled with the explosion of electronic commerce, has created an ever increasing demand for additional IT spending. IT spending, given the uncertainty of returns, could be viewed as inherently riskier than traditional investments. Shareholders, lacking the information available to managers, could potentially demand higher returns to compensate for assuming a higher level of risk.

Investments in IT represent a special case of firm investment that carries greater payoff uncertainty than traditional investments. Dos Santos (1991) indicated several problems with the typical IT investment studies including difficulty in estimating cash flows and lack of immediacy in payoffs. According to Bensaou and Earl (1998), other problems with investment in IT included inadequate payoffs and too much "technology for technology's sake." Agency theory defines a clear link between a firm's investments and its dividend policy. The purpose of this note is to investigate whether management attempts to differentiate between IT investment and projects that fit more traditional capital budgeting models when establishing dividend policy.

\section{Information Technology Investment}

A number of studies have indicated that investors differentiate between the types of investments firms undertake typically resulting in stock price fluctuation. McConnell and Muscarella (1985) found that unanticipated changes in capital expenditure do indeed impact share price positively or negatively depending on the aggregate perception of "good" or "bad" investment decisions. Others such as Statman and Sepe (1989) uncovered market reactions to the termination of certain investment projects while Chauvin and Hirschey (1993) found a positive market reaction to increased firm spending on advertising and research and development. All of these studies used standard event study methodology to gauge market or investor reaction. The authors of these studies, as mentioned earlier, addressed

Readers with comments or questions are encouraged to contact the authors via email. 
managerial decisions that are more readily labeled as "good" or "bad." However, investments in IT were not as easy to classify.

The managerial and financial impacts of investments in IT on the firm continue to be hotly debated. Numerous studies, including Hitt and Brynjolfson (1996) and Kivijarvi and Saarinen (1995), have addressed the relationship between IT investments and some measure of financial performance and/or productivity. These studies found linkages to exist but with the expected productivity and financial payoffs often accruing only in the long-term or when the IT investment is coupled with complementary business strategies. Even then, excessive profits were not necessarily linked to IT investment.

Other researchers, such as Mahmood and Mann (1993), discovered that IT investments were strongly interrelated with strategic and economic performance measures. In their study, various operational definitions related to IT investment variables, such as organizational IT expenditures as a percentage of revenue, percentage of IT budget spent on training, and number of computers and terminals as a percentage of total employees, were found to have impacted such factors as sales by employee, return on sales, and market to book value. Grover et al. (1998) also supported the connection between IT investment and firm strategy. Rai et al. (1997) concluded that the impact of IT investment on productivity and performance possibly depends on management processes and IT-strategy links.

Bharadwaj et al. (1999) argued that the problems associated with accounting measures of firm performance are that traditional accounting measures reflected only historical information and do not adjust for risk. To address these concerns, their study used Tobin's q to measure firm performance. Their research suggested that IT investments indeed positively affect the performance of the firm.

According to Thorp (1999), IT investments were not a technical issue but a business issue. CEOs and all other managers have realized that IT investments only account for a fraction of the total investment that organizations make and that these IT investments are essential.

In assessing the impact of IT investments on firm's performance, this research decomposes investments into two specific cateogories: traditional investments and IT investments. IT investments are perceived to be more risky than its traditional counterpart.

\section{Agency Theory and the Dividend and Investment Linkage}

According to Jensen and Meckling (1976), agency theory addresses the potential difficulties arising from the separation of ownership (stockholders) and management. Stockholders, to ensure management acts in their best interest, force firms to incur monitoring costs. One way that stockholders monitor management is to force firms to periodically enter the external markets seeking capital (Easterbrook, 1984). Higher dividend paying firms are frequently forced to the external markets to secure adequate funds for investment and therefore are more heavily scrutinized by the financial markets during the security issuance process. Thus, in an agency framework, dividend payment serves as a monitoring function.

Conversely, Miller and Rock (1985) maintained that the dividend and investment decision are "flip sides of the same coin." Firms desiring additional investment funds, automatically by default, make lower dividend payments since internally generated funds are the cheapest source of financing. Dividends are only distributed if firms run out of profitable investment options. Firms making investment decisions that are clearly perceived as "good" investments can more easily follow this residual dividend policy and distribute lower payouts. A survey by Baker et al. (1985) indicated that management views the dividend decision as an active policy variable. More recently, Moh'd et al. (1995) concluded that managers appear to adjust dividend payout over time and across firms. If shareholders perceive IT investments to create wealth, regardless of time horizon, firms should be able to distribute lower dividends and be forced less frequently into the external capital markets.

However, investments in IT are a special case of investment. There is no indication to date that IT investment 
consistently results in a positive net present value investment opportunity. This uncertainty, or increased risk surrounding the IT investment decision, could create investor demand for higher dividend distributions to more closely monitor firm management. If so, a positive relationship between IT investment and dividend payout would be expected. This paper aims at examining this proposition empirically.

\section{Dividend Model Specification and Relevant Literature}

This study addresses the issue of the impact of information technology by extending Rozeff's (1982) agency cost/transaction cost tradeoff model of dividend policy. Rozeff maintained that a firm's optimal dividend policy will balance the firm's demand for funds with the investor's demand for bonding management (an agency cost). Firms electing to distribute a cash dividend would be forced into the external capital markets for needed funds and subject themselves to the scrutiny of some third party. This action lowers agency costs but conversely increases transaction costs associated with raising external capital.

A number of recent studies, (Rao and White (1994), Casey et al. (1999), Casey and Dickens (2000) and Noronha et al. (1996)) have used extensions of Rozeff's agency cost/transaction cost tradeoff model to investigate various aspects of dividend policy. Rozeff's original model contained five variables: 1. the percentage of insider ownership, 2. past growth rate of revenues, 3 . expected growth rate of revenues, 4 . a firm's beta, and 5. the natural log of the number of common stockholders. A discussion of the justification for each variable follows.

According to Rozeff (1982), the higher the percentage of stock held by insiders (INS), the lower the dividend payout ratio. Dividend payment functions as a bonding cost by decreasing the time and effort expended by outside ownership to monitor the corporation. If insiders hold a significant portion of shares, the demand for higher dividend payouts falls. Conversely, if insiders own very little of the firm's stock, then higher dividend payouts function to lower monitoring costs.

Rozeff also expected the previous five year average growth rate of revenues (GROW1) to have a negative impact on dividend payout policy. The rationale of this relationship is the higher the past revenue growth, the higher the past demand for investment funds to support that revenue growth. Rozeff considers the forecasted five year revenue growth (GROW2) to be a proxy for future investment capital needs. The expected relationship is also negative. The higher the forecasted revenue growth, the lower the dividend payout ratio, assuming maintenance of a target capital structure.

Rozeff (1982) used beta to proxy a firm's operating and financial leverage. According to Rozeff, a firm with a higher use of total leverage would have a higher beta. Therefore, to lower the cost of external financing, these higher beta firms would choose lower dividend payout ratios. Dividend payout should then be negatively related to beta.

Rozeff hypothesized the dispersion of ownership, as measured by the total number of stockholders, should also affect dividend payout ratios. A smaller number of stockholders would be able to monitor the firm more easily than a larger number. Therefore, as the number of stockholders increases, the likelihood of higher dividend payout ratios also increases. Again, the distribution of dividends functions to reduce monitoring costs. The natural log of the number of shareholders (STOCK) corrects for scale effects.

Rozeff (1982) found all five original variables to be significant in explaining dividend payout. Later studies by Dempsey and Laber (1992) and Dempsey et al. (1993) replicated and extended Rozeff (1982) by examining another seven year period. These studies confirmed the stability of Rozeff's original five variable model.

A specific variable to measure the impact of IT investment on dividend policy will be added to Rozeff's original model. Information management spending data, including sales, administrative, research and development, and other general IT expenses, from several hundred companies were available via the Internet (Strassmann, 1997). In previous studies, IT investments have been measured in a variety of ways including IT expenses as a percentage of revenue (Weill and Olson, 1989) and IT expenses as a percentage of premium income in the insurance industry (Bender, 1986). In this study, the IT variable added to the original model was operationalized as the information management spending as a 
percentage of net income. The authors recognize that there are many different risk-types of IT investment making it problematic to only use a single measure. Unfortunately, lack of data availability precludes separation into IT risk classes for this study. However, the fact that the typical investor also lacks the ability to determine the appropriate risk classification creates even more investor uncertainty. Also because of smallness of sample size, we refrain from assessing interindustry differences at this time.

A presentation of Rozeff's original agency cost/transaction cost tradeoff model and a modified version of it that includes IT investment follows:

$$
\begin{aligned}
& \text { PAY }_{\mathrm{i}}=\alpha_{0}-\alpha_{1} \mathrm{INS}_{\mathrm{i}}-\alpha_{2} \mathrm{GROW}_{\mathrm{i}}-\alpha_{3} \mathrm{GROW}_{\mathrm{i}}-\alpha_{4} \mathrm{BETA}_{\mathrm{i}}+\alpha_{5} \mathrm{STOCK}_{\mathrm{i}}+\varepsilon_{\mathrm{ij}} \\
& \mathrm{PAY}_{\mathrm{i}}=\alpha_{0}-\alpha_{1} \mathrm{INS}_{\mathrm{i}}-\alpha_{2} \mathrm{GROW}_{\mathrm{i}}-\alpha_{3} \mathrm{GROW}_{\mathrm{i}}-\alpha_{4} \mathrm{BETA}_{\mathrm{i}}+\alpha_{5} \mathrm{STOCK}_{\mathrm{i}} \pm \alpha_{6} \mathrm{ITINV}_{\mathrm{i}}+\square \varepsilon_{\mathrm{eij}}
\end{aligned}
$$

Where:

$\mathrm{PAY}_{\mathrm{i}}=$ Dividend payout ratio of firm i for 1995.

$\mathrm{INS}_{\mathrm{i}}=$ Percentage of common stock held by insiders for firm $\mathrm{i}$.

GROW $1_{\mathrm{i}}=$ Realized five year average growth rate of revenues for firm $\mathrm{i}$.

GROW $2_{\mathrm{i}}=$ Forecasted future five year average growth rate for firm $\mathrm{i}$.

BETA $_{i}=$ Firm i's beta coefficient.

STOCK $_{i}=$ Natural logarithm of number of common stockholders for firm $i$.

ITINV $_{\mathrm{i}}=$ Firm i's information management spending in 1995 as a percentage of net income.

$\varepsilon_{\mathrm{ij}}=$ error term independently and identically distributed as $\mathrm{N}\left(0, \square_{\mathrm{j}}^{2}\right), \mathrm{j}=1,2$.

Note that the operational signs indicate the hypothesized direction of the impact each variable should have on dividend payout policy in both models. For this study, $\mathrm{PAY}_{\mathrm{i}}$ is calculated using a one year dividend payout ratio consistent with Moh'd et al. (1995). Rozeff's original study used a seven year period while Dempsey and Laber (1992) used alternative two-year and four-year mean payout definitions and found the model to be robust over these shorter time horizons.

\section{The Sample}

One hundred seventy-two firms were selected from the 1995 Global Information Productivity Rankings (Strassmann, 1997). These firms were cross-referenced with Compact Disclosure, which was used to provide the financial data for the study. Fifty-two firms were discarded due to 1) unavailability of financial data, 2) no dividends were paid during 1995, and/or 3) the related dividend payout ratios were negative. Table 1 depicts the number of firms from each industry out of the one hundred twenty firms included in the final analysis.

Table 2 shows descriptive statistics related to the variables used in the study. The table illustrates considerable variability associated with each studied variable. Table 3 displays the correlation coefficients between the explanatory variables as well as between them and the dependent variable. The table indicates that all Pearson correlation coefficients between each of the independent variables and PAY are significant $(\mathrm{p} \leq 0.065)$. All of such coefficients have the expected signs as depicted in model 1. Furthermore, the correlation between the variable ITINV in model 2 and PAY appears to be positive. The presence of significant correlation among some of the independent variables is indicative that the estimated regression equations might include insignificant term(s). 


\begin{tabular}{|lc|}
\hline \multicolumn{2}{|c|}{$\begin{array}{c}\text { Table 1 } \\
\text { Number of firms included in study by } \\
\text { industry }\end{array}$} \\
Apparel & \\
Automotive & 4 \\
Beverages & 3 \\
Chemical & 3 \\
Construction & 8 \\
Diversified & 5 \\
Drugs/Health & 10 \\
Electrical & 10 \\
Electronics & 2 \\
Food & 6 \\
Machinery & 10 \\
Metals & 6 \\
Miscellaneous & 4 \\
Paper & 9 \\
Petroleum & 3 \\
Printing & 9 \\
Recreation & 2 \\
Retail & 8 \\
Textiles & 9 \\
Transportation & 2 \\
Utilities & 2 \\
Total & 5 \\
\hline
\end{tabular}

\section{Estimation Results}

Regression models 1 and 2 were estimated using the method of ordinary least squares (OLS). The estimation results related to models 1 and 2 are depicted in Table 4.

Model 1 has an F-ratio of 5.315 that is significant $(\mathrm{p}<0.01)$. The coefficient of determination $\mathrm{R}^{2}$ indicates that $18.9 \%$ of the variance in the dividend payout ratio is explained by the related independent variables. The coefficients of the variables historical growth rate (GROW1), predicted growth rate (GROW2), and natural $\log$ of the number of stockholders (STOCK) are significant ( $\mathrm{p}<0.05$ ) in the regression equation. All coefficients in the estimated model show the appropriate signs even when the parameter estimates were not significant.

Model 2 appears to be much more robust with an $\mathrm{R}^{2}$ of .291 and an F-ratio of 7.715 that is significant $(\mathrm{p}<0.01)$. For this model, the coefficients related to GROW1, GROW2, STOCK, and the IT investment variable (ITINV) are significant $(\mathrm{p}<0.05)$. The information technology (ITINV) coefficient is positive and significant at the 0.01 level indicating the existence of a significant positive relationship between IT spending and the dividend payout ratio.

A reduced model, model 3, was derived from the full model 2 upon setting the coefficients of both the variables BETA and INS, that were insignificant in model 2, to zero. The estimation results of the reduced model are shown in Table 4. Model 3 appears to be robust, as well, with an $\mathrm{R}^{2}$ of .280 , which is close to that of model 2, and an F-ratio of 11.153 that is also significant $(\mathrm{p}<0.01)$. All coefficients included in the reduced model are significant at the 0.02 level. It is worthy to mention at this point that when expression (2) was estimated using a forward stepwise regression procedure for which $\alpha=0.05$, the estimates related to model 3 were exactly reproduced. The initial variable to enter the model was ITINV with a corresponding $\mathrm{R}^{2}$ value of 0.087 . This quantity represents $31.07 \%$ of the $\mathrm{R}^{2}$ magnitude reported for model 3 , with all four variables included. In addition, the absolute value of the partial correlation coefficient (these coefficients are independent of the units of measurement and show the correlation between the independent variable when the influence of other independent variables are held constant) attains its largest value for the variable ITINV (see last remark in Table 4). Some writers (e.g. Neter et al., 1990) use such coefficients to compare the impact of variables in multiple regression. Accordingly, we may conclude that the ITINV variable has the largest influence on the dependent variable PAY.

An examination of variance inflation factors (Neter et al., 1990) was performed to address multicollinearity. The analysis did not suggest that multicollinarity was an issue. Furthermore, there were no indications that heteroscadasticity was a problem (White, 1990) adding more credence to the robustness of the model. Finally, after careful examination of studentized deleted residuals and leverage values (Neter et al., 1990), eleven outliers were detected. A follow up diagnostic analysis using DFFITS, Cook's D, and DFBETAS revealed, however, that the outliers were not influential. Accordingly, no observations were required to be deleted (Neter et al., 1990). A description of the diagnostics mentioned above is found in the Appendix. 
Table 2:

Descriptive statistics of variables used.

\begin{tabular}{llllll}
\hline \multicolumn{1}{c}{ Variable } & \multicolumn{1}{c}{ Mean } & Standard Deviation & Minimum & Maximum & Coefficient of Variation \\
\hline \multirow{2}{*}{ INS } & 0.052 & 0.091 & 0.000 & 0.522 & 1.750 \\
GROW1 & 2.951 & 1.882 & 0.080 & 11.290 & 0.638 \\
GROW2 & 12.106 & 3.208 & 3.900 & 29.200 & 0.265 \\
BETA & 1.010 & 0.347 & 0.151 & 2.519 & 0.344 \\
STOCK & 70.648 & 136.974 & 70.648 & 136.973 & 1.938 \\
ITINV & 2.488 & 3.991 & 0.0002 & 24.207 & 1.604 \\
PAY & 0.428 & 0.307 & 0.018 & 2.000 & 0.717 \\
\hline INS: $\%$ in
\end{tabular}

INS: \% insider ownership

GROW1: Historical 5 year growth rate

GROW2: Predicted 5 year growth rate

BETA: Corporate beta

STOCK: Number of stockholders (millions)

ITINV : Information management expenditures as a percentage of net income

PAY: Dividend payout ratio (dependent variable)

Table 3:

Pearson correlation coefficients among variables.

\begin{tabular}{|c|c|c|c|c|c|c|c|}
\hline Variable & INS & GROW1 & GROW2 & BETA & LNSTOCK & ITINV & PAY \\
\hline INS & 1.000 & & & & & & \\
\hline GROW1 & -.146 & 1.000 & & & & & \\
\hline GROW2 & $.292 * *$ & $-.369 * *$ & 1.000 & & & & \\
\hline BETA & .024 & .068 & $.228 *$ & 1.000 & & & \\
\hline LNSTOCK & $-.245^{* *}$ & .125 & -.126 & -.050 & 1.000 & & \\
\hline ITINV & .106 & $-.356 * *$ & .146 & -.110 & $-.353 * *$ & 1.000 & \\
\hline PAY & $-.170^{\mathrm{a}}$ & $-.198 *$ & $-.207 *$ & $-.202 *$ & $.199 *$ & $.295 * *$ & 1.000 \\
\hline
\end{tabular}

INS: \% insider ownership

GROW1: Historical 5 year growth rate

GROW2: Predicted 5 year growth rate

BETA: Corporate beta

LNSTOCK: Natural log of the number of stockholders (millions)

ITINV : Information management expenditures as a percentage of net income

PAY: Dividend payout ratio (dependent variable)

* Significant at the 0.05 level

** Significant at the 0.01 level

${ }^{\text {a }} \mathrm{P}$-value $=0.064$ 
Table 4:

OLS regression results for dividend payout ratios.

\begin{tabular}{lccc}
\hline $\begin{array}{l}\text { Independent } \\
\text { Variables }\end{array}$ & Regression Model 1 & Regression Model 2 & Regression Model $3^{\text {a }}$ \\
\hline Constant & 0.284 & -0.328 & -0.454 \\
& $(.425)$ & $(0.384)$ & $(0.372)$ \\
INS & -0.329 & -0.302 & $-0.0351^{*}$ \\
& $(0.305)$ & $(0.287)$ & $(0.015)$ \\
GROW1 & $-0.0519^{* *}$ & $-0.0340^{*}$ & $-0.0288^{* *}$ \\
GROW2 & $(0.015)$ & $(0.015)$ & $(0.008)$ \\
BETA & $-0.0237^{*}$ & $-0.0246^{* *}$ & $(0.009)$ \\
TOCK & $(0.009)$ & -0.0635 & $(0.019)$ \\
ITINV & -0.0993 & $(0.074)$ & $0.0288^{* *}$ \\
R & $(.078)$ & $0.0679^{* *}$ & $(.007)$ \\
F-statistic & $0.0409^{*}$ & $(0.020)$ & .280 \\
Prob. $>$ F & $(0.020)$ & $0.0280^{* *}$ & $11.153^{* *}$ \\
N & & $(.007)$ & .000 \\
\hline Standar & .189 & .291 & 120 \\
\hline
\end{tabular}

Standard error of estimated coefficients are reported in parentheses

* Significant at the 0.05 level

** Significant at the 0.01 level

a Partial correlation coefficients for variables GROW1, GROW2, STOCK, and ITINV are $-0.218,-0.312,0.332$, and 0.363 respectively

When more parameters are in a model, the goodness of fit of the model measured in terms of $\mathrm{R}^{2}$ improves (Neter et al., 1990). If the sum of squares of errors in the full model, SSE(F), is not much less than the sum of squares of errors in the reduced model, SSE(R), using the full model does not account for much more of the variability in the dependent variable (Neter et al. , 1990). To put this another way, when $\operatorname{SSE}(\mathrm{F})$ is close to the $\operatorname{SSE}(\mathrm{R})$, the variation of the observations around the fitted regression equation for the full model is almost as great as the variation around the fitted regression equation for the reduced model. In this case, the added coefficients in the full model really do not help to reduce the variation in the dependent variable about the fitted regression equation. In order to test the appropriateness of the reduced model (Model 3), the following test statistic (3) is computed using the information contained in the ANOVA tables pertaining to Models 2 and 3 shown in Table 5:

$\mathrm{F}^{*}=\frac{\operatorname{SSE}(\mathrm{R})-\operatorname{SSE}(\mathrm{F})}{d f_{\mathrm{R}}-d f_{\mathrm{F}}} \div \frac{\operatorname{SSE}(\mathrm{F})}{d f_{\mathrm{F}}}$

Where:

SSE $(F)=$ Sum of Squares of the error terms of the full model $($ Model 2$)=7.946$.

SSE $(\mathrm{R})=$ Sum of Squares of the error terms of the reduced model $($ Model 3$)=8.068$.

$d f_{\mathrm{F}}=$ degrees of freedom in the full model $=113$.

$d f_{\mathrm{R}}=$ degrees of freedom in the reduced model $=115$. 


\begin{tabular}{|cccc|}
\hline \multicolumn{4}{l}{ Table 5: } \\
\hline Model & Source of Variation & Sum of Squares & df \\
\hline 2 & Regression & 3.254 & 6 \\
& Residual & 7.946 & 113 \\
& Total & 11.198 & 119 \\
3 & Regression & 3.130 & 4 \\
& Residual & 8.068 & 115 \\
& Total & 11.198 & 119 \\
\hline
\end{tabular}

The calculated value of $\mathrm{F}^{*}$ was only 0.889 whereas tabulated $\mathrm{F}_{(0.05 ; 2,113)}=3.09$ implying that the reduced model provides almost as much explanatory information about the dependent variable, PAY, as the full model. This indicates that the reduced model (Model 3) derived from the full model (Model 2) is appropriate.

\section{Comparison of Models}

We first note that Rozeff's original model (Model 1) and its reduced modified version that includes an IT investment variable (Model 3) are two non-nested models. (Two models are said to be non-nested if one model cannot be obtained from the other through equating some coefficients in the first (second) model to zero in order to produce the second (first) model.) To test the null hypothesis that these two competing non-nested models are equally close to the true data generating process against the alternative hypothesis that one model is closer, a J-test proposed by Davidson and MacKinnon (1981) is employed (See Appendix for details). Designating Model 1 as $f$ and Model 3 as $g$, the J-test entails estimating the following two compound models:

$\mathrm{PAY}_{\mathrm{i}}=\left(1-\alpha_{\mathrm{N}}\right) \mathrm{f}_{\mathrm{i}}+\alpha_{\mathrm{N}} \hat{g}_{i}+\varepsilon_{\mathrm{Ni}}$

$\mathrm{PAY}_{\mathrm{i}}=\left(1-\alpha_{\mathrm{A}}\right) \mathrm{f}_{\mathrm{i}}+\alpha_{\mathrm{N}} \hat{\mathrm{f}}_{i}+\varepsilon_{\mathrm{Ai}}$

where $\alpha_{\mathrm{N}}$ and $\alpha_{\mathrm{A}}$ are regression coefficients to be estimated, while $\square{ }_{\mathrm{Ni}}$ and $\square_{\mathrm{Ai}}$ are error terms. Davidson Davidson and MacKinnon (1981) showed that the t-statistic of $\alpha_{\mathrm{N}}$ is asymptotically normal $(\mathrm{N}(0,1))$ when model $f$ is the preferred one, whereas the t-statistic of $\alpha_{\mathrm{A}}$ is asymptotically normal $(\mathrm{N}(0,1))$ when model $g$ is the preferred one.

Since the OLS results associated in estimating equations (4) and (5) show that the estimated $\alpha_{N}$ coefficient is statistically significantly different from zero at better than the $\square=0.05$ level $(t=4.022)$ and the estimated $\alpha_{A}$ coefficient is not statistically significantly different from zero at the same level $(\mathrm{t}=1.311)$, we conclude that Model 3 is preferred to Model 1 as it appears to be better supported by the data (see decision rules in the Appendix for more details.)

\section{Conclusions}

Partington (1985), in a survey of Australian firms, identified several important managerial motives for dividend payout. His study indicated that management viewed dividend policy as an active managerial tool consistently used to convey information to shareholders. Managers, therefore, should consider the impact of various investments on the shareholders and allay shareholders concerns via dividend distribution. The primary contribution of this paper is that it clearly identifies an agency connection between dividend policy and IT investment. The significant positive sign on IT investment indicates that management believes investment in IT warrants additional dividend distribution to reduce agency costs. Further research is needed to fully understand the relationship between IT investments and other managerial decisions.

\section{Suggestions for Future Research}

Much of the previous work in this area treats the IT investment decision in isolation. As this research indicates, the IT investment decision impacts other previously unrecognized areas of the firm. Additional research should focus on the interrelationships between the IT investment decision and other managerial decisions. 


\section{References}

1. Baker, H.K., Farrelly, G.E., \& Edelman, R.B. (1985). A survey of management views on dividend policy. Financial Management, 14, 78-84.

2. Bender, D. (1986). Financial impact of information processing. Journal of Management Information Systems, 3(2), 232-238.

3. Bensaou, M., \& Earl, M. (1998). The right mind-set for managing information technology. Harvard Business Review, 76(5), 118-128.

4. Bharadwaj, A., Bharadwaj, S., \& Konsynski, B. (1999). Information technology effects on firm performance as measures by Tobin's q. Management Science, 45(6), 1008-1024.

5. Casey, K. M., Anderson, D., Mesak, H., \& Dickens, R. (1999). Examining the impact of the 1986 tax reform act on corporate dividend policy: a new methodology. The Financial Review, 34(3), 33-46.

6. Casey, K. M., \& Dickens, R. (2000). The effects of tax and regulatory changes on commercial bank dividend policy. Quarterly Review of Economics and Finance, 40, 279-293.

7. Chauvin, K. W., \& Hirschey, M. (1993). Advertising, R\&D Expenditures and the Market Value of the Firm. Financial Management, 22(40), 128-140.

8. Davidson, R., \& MacKinnon, J.H. (1981). Several tests for model specification in the presence of alternative hypothesis. Econometrica, 49, 781-793.

9. Dempsey, S. J., \& Laber, G. (1992). Effects of agency and transaction costs on dividend payout ratios: further evidence of the agency-transaction cost hypothesis. The Journal of Financial Research, 15, 317-321.

10. Dempsey, S. J., Laber, G., \& Rozeff, M. (1993). Dividend policies in practice: is there an industry effect? Quarterly Journal of Business and Economics, 32, 3-13.

11. Dos Santos, B. L. (1991). Justifying investments in new information technologies. Journal of Management Information Systems, 7(4), 71-90.

12. Easterbrook, F, H. (1984). Two agency-cost explanations of dividends. American Economic Review, 74(4), 650-659.

13. Grover, V., Teng, J. T. C., \& Fiedler, K. D. (1998). IS investment priorities in contemporary organizations. Communications of the ACM, 41(2), 40-48.

14. Hitt, L. M., \& Brynjolfsson, E. (1996). Productivity, business profitability, and consumer surplus: three different measures of information technology value. MIS Quarterly, 20(2), 121-142.

15. Kivijarvi, H., \& Saarinen, T. (1995). Investment in information systems and the financial performance of the firm. Information and Management, 28, 143-163.

16. Jensen, M., \& Meckling, W. (1976). Theory of the firm: managerial behavior, agency costs, and ownership structure. Journal of Financial Economics, 3, 305-360.

17. Mahmood, M. A., \& Mann, G. J. (1993). Measuring the organizational impact of information technology investment: an exploratory study. Journal of Management Information Systems, 10(1), 97-122.

18. McConnell, J. J., \& Muscarella, C. J. (1985). Corporate capital expenditure decisions and the market value of the firm. Journal of Financial Economics, 14(3), 399-422.

19. Miller, M. H., \& Rock, K. (1985). Dividend payout under asymmetric information. Journal of Finance, 40, 1031-1051.

20. Moh'd, M. A., Perry, L. G., \& Rimbey, J. N. (1995). An investigation of the dynamic relationship between agency theory and dividend policy. The Financial Review, 30(2), 367-385.

21. Neter, J, Wasserman, W., \& Kutner, M. H. (1990). Applied Linear Statistical Models, Third Edition, Irwin Press (Homewood, IL).

22. Noronha, G. M., Shome, D. K., \& Morgan, G. E. (1996) The monitoring rationale for dividends and the interaction of capital structure and dividend decisions. Journal of Banking and Finance, 20(3), 439-454.

23. Partington, G. H. (1985). Dividend policy and its relationship to investment and financing policies: empirical evidence. Journal of Business Finance and Accounting. 12(4), 531-542.

24. Rai, A., Patnayakuni. R., \& Patnayakuni, N. (1997). Technology investment and business performance. Communications of the ACM, 40(7), 89-97.

25. Rao, R., \& White, Susan A. (1994). The dividend payouts of private firms: evidence from tax court decisions. The Journal of Financial Research, 17(4), 449-464. 
26. Rozeff, M.S. (1982). Growth, beta, and agency costs as determinants of dividend payout ratios. Journal of Financial Research, 5, 249-259.

27. Statman, M., \& Sepe, J. F. (1989). Project termination announcements and the market value of the firm. Financial Management, 18(4), 74-81.

28. Strassmann, P. (1997). Global Information Productivity Rankings, www.strassmann.com.

29. Thorp, J. (1999). Computing the payoff from IT. Journal of Business Strategy, 20(3) 35-39.

30. Turner, J., \& Lucas, H. (1985). Developing strategic information systems. Handbook of Business Strategy, Warren, Gorham, and Lamont, Boston, 1-21.

31. Weill, P., \& Olson, M. (1989). Managing investments in information technology: mini case examples and implications. MIS Quarterly, 13(1), 3-16.

32. White, H. (1980) A heteroscedasticity consistent covariance matrix" Econometrica, 817-838.

\section{Appendix}

The J Test

Consider the null $\left(\mathrm{H}_{\mathrm{N}}\right)$ and alternative $\left(\mathrm{H}_{\mathrm{A}}\right)$ hypotheses represented by the following non-nested models:

$\mathrm{H}_{\mathrm{N}}: \mathrm{Y}_{\mathrm{i}}=f_{\mathrm{i}}\left(\mathbf{X}_{\mathrm{i}}, \square \gamma\right)+\varepsilon_{\mathrm{Ni}}$

$\mathrm{H}_{\mathrm{A}}: \mathrm{Y}_{\mathrm{i}}=g_{\mathrm{i}}\left(\mathbf{Z}_{\mathrm{i}}, \square \gamma\right)+\varepsilon_{\mathrm{Ai}}$

Where

$Y_{i}$ the the i-th observation on the dependent variable,

$\mathbf{X}_{\mathrm{i}}$ and $\mathbf{Z}_{\mathrm{i}}$ are vectors of observations on exogenous variables,

$\boldsymbol{\beta}$ and $\boldsymbol{\gamma}$ are coefficient vectors to be estimated, and

$\varepsilon_{\mathrm{Ni}}$ and $\varepsilon_{\mathrm{Ai}}$ are error terms assumed to be $\operatorname{NID}\left(0, \square \sigma_{\mathrm{N}}{ }^{2}\right)$ and $\operatorname{NID}\left(0, \square \sigma_{\mathrm{A}}{ }^{2}\right)$, respectively.

The J-test equation is given by the following artificial regression equation:

$Y_{i}=\left(1-\alpha_{N}\right) f_{i}\left(X_{i}, \beta\right)+\alpha_{N} \hat{g}_{i},+\varepsilon_{N i}$

Where

$\hat{g}_{i}=\mathrm{g}_{\mathrm{i}}\left(\mathbf{Z}_{\mathbf{i}}, \hat{\gamma}\right), \hat{\gamma}$ is the least squares estimate of $\gamma$ derived from estimating equation (A.2),

$\alpha_{\mathrm{N}}$ is a regression coefficient, and $\varepsilon_{\mathrm{Ni}}$ is an error term.

The J-test considers that $H_{N}$ is true if $\alpha_{N}$ equals zero; if $\alpha_{N}$ is significantly different from zero, $H_{N}$ is rejected.

Because the J-test is an asymmetric test, it is necessary to reverse the roles of $\mathrm{H}_{\mathrm{N}}$ and $\mathrm{H}_{\mathrm{A}}$ in equations (A.1) and (A.2), and the corresponding version of equation (A.3) becomes

$\mathrm{Y}_{\mathrm{i}}=\left(1-\alpha_{\mathrm{A}}\right) \mathrm{g}_{\mathrm{i}}\left(\mathbf{Z}_{\mathrm{i}}, \gamma\right)+\alpha_{\mathrm{A}} \hat{f}_{i},+\varepsilon_{\mathrm{Ai}}$

where

$\hat{f}_{i}=f_{\mathrm{i}}\left(\mathbf{X}_{\mathrm{i}}, \hat{\beta}\right), \hat{\beta}$ is the least squares estimate of $\gamma$ derived from estimating equation (A.1), $\alpha_{\mathrm{A}}$ is a regression coefficient, and $\varepsilon_{\mathrm{Ai}}$ is an error term. 
The execution of the J-test leads to one of the four conclusions depicted in the following table.

Possible types of results from the J-test

\begin{tabular}{lll}
\hline Type & Regression Results & Conclusion from Tests \\
\hline 1 & $\alpha_{A}=0 ; \alpha_{N}=0$ & \\
2 & $\alpha_{A} \neq 0 ; \alpha_{N}=0$ & Neither $\mathrm{H}_{\mathrm{A}}$ nor $\mathrm{H}_{\mathrm{N}}$ can be rejected \\
3 & $\alpha_{\mathrm{A}}=0 ; \alpha_{\mathrm{N}} \neq 0$ & Reject $\mathrm{H}_{\mathrm{A}} ;$ accept $\mathrm{H}_{\mathrm{N}}$ \\
4 & $\alpha_{\mathrm{A}} \neq 0 ; \alpha_{\mathrm{N}} \neq 0$ & Accept $\mathrm{H}_{\mathrm{A}} ;$ reject $\mathrm{H}_{\mathrm{N}}$ \\
\hline
\end{tabular}

\section{Description of Diagnostics}

Variance Inflation Factors: These factors measure how much the variances of the estimated regression coefficients are inflated as compared to when the independent variables are not linearly related.

Studentized Deleted Residuals: For a certain observation, it represents the difference between the actual value of the dependents variable and its expected value relative to its standard error, after the deletion of that observation.

Leverage Values: For a certain observation, it measures the distance between the independent variable related to that observation and the center of such variables.

DFFITS: It represents the difference between the fitted value of the dependent variable for a certain observation when all $\mathrm{N}$ observations are used in fitting the regression equation and the predicted value of the same when the observation is omitted in fitting the equation.

Cook's Distance Measure: It considers the influence of a certain observation on all the $\mathrm{N}$ fitted values of the dependent variable.

DFBETAS: It shows for a particular observation the difference in estimating a certain regression coefficient relative to its estimated standard error upon the deletion of the observation from the regression analysis.

(For more details regarding the above diagnostics, see Neter et al. (1990) 
Notes 